ASK BLACK MOTHERS ABOUT VIOLENCE IN COVID-19

But Is It Okay? The Need to Still Ask Black/African American Mothers About Violence Exposure During The COVID-19 Worldwide Pandemic

Jennifer M. Gómez \& Ty Partridge

Under Review For Publication

25 June 2021 
ASK BLACK MOTHERS ABOUT VIOLENCE IN COVID-19

\begin{abstract}
Black/African American communities endure the double pandemic of COVID-19 and policeand civilian-perpetrated anti-Black violence, with Black/African American mothers at risk for exposure to violence in the home. Questions remain about the potential harm in asking about violence exposure, particularly in the current climate. The purpose of the study is to examine Black/African American mothers' reactions to participating in violence research during the COVID-19 pandemic in the U.S. Participants $(N=127$; Age: $M=32.46$ years, $S D=5.61$ years $)$ were Black/African American mothers living in an urban, predominantly Black city in the Midwestern U.S. who completed online measures of exposure to violence before, during, and after shelter-in-place orders, as well as their reactions to participating in violence research. We found that the majority of participants did not find participation more distressing than other day to day experiences, with $100 \%$ of those with violence histories reporting such research is important. The current study's findings can promote inclusion of violence measures in research and healthcare settings, with results guiding trauma-informed care for Black/African American mothers.
\end{abstract}

Key Words: violence; sexual assault; cultural betrayal trauma theory; COVID-19; Black/African American mothers 
ASK BLACK MOTHERS ABOUT VIOLENCE IN COVID-19

\section{But Is It Okay? The Need to Still Ask Black/African American Mothers About Violence Exposure During The COVID-19 Worldwide Pandemic}

The COVID-19 pandemic has wreaked havoc on the Black/African American community, with inequities (Hooper et al., 2020; Laurencin \& McClinton, 2020) resulting in approximately one-third of all cases in the U.S. being Black/African Americans (Centers for Disease Control and Prevention, 2020). Additionally, in the U.S., this physical health pandemic has occurred in tandem with the second pandemic of police- and civilian-perpetrated anti-Black violence, resulting in societal unrest in the forms of rebellions and protests (Dreyer, 2020). Simultaneously operating under the radar is violence within the home, which has continued and potentially increased for women and mothers during governmental shelter-in-place orders related to COVID-19 (American Psychological Association, 2020; Campbell, 2020; Evans et al., 2020), particularly in Black and other women of Color (Ruiz et al., 2020). Therefore, it remains important for researchers and community practitioners to continue to assess for exposure to violence (e.g., Holland et al., 2020) in order to guide efforts. However, there are likely concerns about the psychological safety of inquiring about violence, perhaps especially in a time of such increased stress, societal unrest, sickness, and death. Therefore, the purpose of the current study is to examine Black/African American mothers' reactions to participating in violence research during the beginning of the COVID-19 pandemic in the U.S.

Insert Figure 1 about here

\section{Exposure to Violence in the Black Community}


ASK BLACK MOTHERS ABOUT VIOLENCE IN COVID-19

Violence exposure, including physical and sexual abuse, is consistently linked with poor mental health (DePrince et al., 2012; Gómez et al., 2014). Shelter-in-place orders during COVID-19 may put women and mothers at increased risk for violence exposure within the home (e.g., Campbell, 2020). This is disproportionately true for Black and other women of Color (Ruiz et al., 2020). Due to the context of inequality (Figure 1), exposure to violence within the Black community may include additional layers of harm. According to cultural betrayal trauma theory (CBTT; Gómez \& Gobin, 2020), some Black people develop (intra)cultural trust, which is Black solidarity, in order to survive and thrive amidst the societal trauma of anti-Black racism, including police brutality, mass incarceration (e.g., Alexander, 2012), and racial discrimination in healthcare (e.g., Gómez, 2015; Institute of Medicine, 2002; Snowden \& Yamada, 2005). Therefore, violence happening within the Black community is a violation of this (intra)cultural trust - it is a cultural betrayal. These cultural betrayal traumas (also known as within-group violence) are linked with typical abuse outcomes, such as mental health, as well as cultural outcomes, such as internalized prejudice (Gómez \& Gobin, 2020). Given misogynoir, or sexism within the Black community (Bailey, 2016), Black women are at risk for physical and sexual violence. Research with Black and other marginalized emerging adults has found that cultural betrayal traumas are associated with depression, dissociation, anxiety, hallucinations, PTSD, sleep problems, changes to ethnic identity, and internalized prejudice (Gómez, 2017a, 2017b, 2019a, 2019b, 2019c, 2019d, 2020a; Gómez \& Freyd, 2018). Therefore, the impact of violence in the Black community — particularly for women and mothers — may be further exacerbated by this cultural betrayal that exists as a by-product of anti-Black racism (Figure 2).

Insert Figure 2 about here 
ASK BLACK MOTHERS ABOUT VIOLENCE IN COVID-19

\section{Is It Okay to Ask About Violence Exposure?}

Though worries about the appropriateness and safety of asking about violence exposure may be heightened in the context of the double pandemic of COVID-19 and racism for Black/African American mothers, the concern of asking about violence exposure in research is not a new one (e.g., Dalenberg, 2013). University institutional review boards often weigh concerns about the harm of asking about violence exposure, including upsetting participants, stigmatizing participants due to their exposure to violence, and conceptualizing survivors of violence as too fragile to participate in violence research (Becker-Blease \& Freyd, 2006, 2007; Black \& Black, 2007; Griffin et al., 2003). Though these concerns come from genuinely wanting to protect participants from being harmed in research, they are misguided in important ways. First, extant research finds that participating in violence research results in mild, transitory distress at worst for most participants, with those who have experienced violence reporting only slightly higher rates of distress (e.g., Cook et al. 2011; DePrince \& Chu, 2008; Edwards et al., 2009; Galea et al., 2005; Gómez et al., 2015; Yeater et al., 2012). Second, participants of violence research themselves report that they believe that violence research is important (Cromer et al., 2006; DePrince \& Freyd, 2006; Gómez et al., 2015; Yeater et al., 2012), with those who have experienced violence reporting increased importance in this research (Edwards et al., 2007; Gómez et al., 2015; Yeater et al., 2012). Third, barriers to violence research (Dalenberg, 2013) may actually reinforce stigma related to violence exposure (Ahrens, 2006; Fontes, 2004) by removing autonomy from research participants (Black \& Black, 2007) through a paternalistic stance that bars self-determination and choice of participants to engage in research (BeckerBlease \& Freyd, 2006; Cook et al., 2015; Fontes, 2004; Griffin et al., 2003). 
ASK BLACK MOTHERS ABOUT VIOLENCE IN COVID-19

Finally, a question that is asked far less often is: What is the harm of not asking about violence exposure? With one of the primary goals of violence research being promoting social justice (Campbell, 2009), one harm of not asking about violence exposure is erasure (Gleaves et al., 2007). In not asking, researchers and community practitioners implicitly condone violence through silence (Herman, 1997), as violence thrives in secrecy. This may be particularly true in the Black community, as cultural mandates for silence stem from misogynoir and racial loyalty to protect Black people from racism at the expense of Black women and girls who are being abused (e.g., Bell \& Mattis, 2000; Bent-Goodley, 2001; Gómez \& Gobin, 2020; Neville \& Pugh, 1997; Tillman et al., 2010; Washington, 2001).

Additionally, given violence exposure's link with deleterious mental and physical health, the fields of psychology, social work, medicine, and public health are additionally left with incomplete data that can result in erroneous conclusions when violence exposure is excluded from conceptualizations of health (e.g., Gómez, Becker-Blease, et al., 2015). Therefore, when we - the researchers, community practitioners, and front-line workers - do not ask about violence exposure, we unwittingly contribute to the aforementioned costs of not asking, while missing crucial aspects of our participants', patients', clients', and community members' lives.

\section{Purpose of the Study}

The COVID-19 worldwide pandemic, along with all the increased stress associated with it, have disproportionately impacted Black/African Americans in the U.S. (Center for Disease Control \& Prevention, 2020). Unfortunately, exposure to violence in the home is part of the context of the pandemic, potentially putting women and mothers at increased risk (Campbell, 2020). Such exposure to violence is not inconsequential. The mental health impact of violence generally (e.g., DePrince et al., 2012) and within the Black community specifically (e.g., Bent- 
ASK BLACK MOTHERS ABOUT VIOLENCE IN COVID-19

Goodley, 2001; Gómez \& Gobin, 2020) is impacted by the context of inequality (e.g., CBTT;

Gómez, 2019a). Therefore, inquiring about exposure to violence is even more necessary in the present context. Though past research has shown that participating in violence research is not harmful (e.g., Gómez et al., 2015), the question for researchers and community practitioners remains: Will asking about violence exposure harm Black/African American mothers, especially during the double pandemic of COVID-19 and anti-Black violence in the U.S.? Therefore, the purpose of the current study is to examine Black/African American mothers' reactions to participating in violence research during the beginning of the COVID-19 pandemic in the U.S. Specifically, we hypothesized that the majority of Black/African American mothers who participate in violence research in Spring-Summer 2020 report:

H1: Distress

H1a: Low rates of reported distress following participation

H1b: Survivors of violence would report higher rates of distress

H2: Importance

$\mathrm{H} 2 \mathrm{a}$ : High rates of perceived importance of violence research following participation

$\mathrm{H} 2 \mathrm{~b}$ : Survivors of violence would report higher rates of perceived importance of violence research

H3: Support to Include Violence Measures in Research

H3a: High rates of support to include violence measures in research

H3b: Survivors of violence would report higher rates of support to include violence measures in research

Finally, we explored if there were differences in participants' reactions to participating in violence research based on depression and anxiety symptoms. 
ASK BLACK MOTHERS ABOUT VIOLENCE IN COVID-19

\section{Method}

\section{Participants \& Procedure}

Participants $(N=127$; Age: $M=32.46$ years, $S D=5.61$ years $)$ were Black/African American mothers from an urban, predominantly Black/African American city in the Midwest, who were recruited from three existing participant registries (masked for peer review) and participated in two Waves. Wave 1 data collection took place between the beginning of April and the middle of June 2020. Wave 2 data collection took place in August 2020. For each wave, potential participants received up to four text messages - one initial and three remindersinviting participation, with participants from one registry additionally receiving a phone call. Characteristics of the survey and compensation were the same for each Wave: online surveys took approximately 20 minutes to complete, and participants were compensated $\$ 10$ for their time through a Target gift card or money on their Clincard. The university institutional review board (IRB) approved the current study. Demographic characteristics for the study sample are provided in Table 1.

\section{Insert Table 1 about here}

\section{Measures}

The current study is part of a large data collection on the impact of COVID-19 on urban parents (author citation), therefore, only some of the measures are reported here.

\section{Exposure to Violence History}

Created by the first author for the current study, Wave 1 of the current study included two questions about exposure to sexual or physical violence in the home. Specifically, participants 
ASK BLACK MOTHERS ABOUT VIOLENCE IN COVID-19

were asked to report whether or not there had been any occurrences of violence in the home (e.g., hitting, pushing, shoving, yelling, screaming) and any forced sexual activity (e.g., sexual touching without consent). Behavioral experiences, such as trauma exposure, are not latent constructs and therefore do not require multiple items to accurately assess. This is especially important in conducting community-based research where measurement brevity is critical. Further, we are assessing experiences of violence and forced sexual activity inclusively and differentiating between different specific instances or types (e.g., hitting v. yelling) are not germane to the research questions being posed in this study. Responses were dichotomous with Yes, No, and Prefer not to answer options. Participants were asked to respond to these questions in reference to any violence before COVID-19 shelter-in-place orders were issued on March 21, 2020 and if these events occurred after the shelter-in-place orders were issued.

Created by the first author for the current study, Wave 2 of the current study included two items assessing exposure to recent physical and sexual violence during the COVID-19 pandemic, with responses of Yes, No, Prefer not to answer. Items: 1) In summer, has there been any violence in the home, such as hitting, pushing, shoving, yelling or screaming?; 2) In summer, has there been any forced sexual activity in the home, such as sexual touching without consent?

The aforementioned items from Wave 1 and Wave 2 were further combined into a dichotomous variable indicating whether the participant had reported any violence exposure or not. With our hypotheses pertaining to any type of violence (e.g., physical, sexual), a single item indicating the occurrence at any level of exposure of any type of violence is sufficient to capture participants' experiences. Scores were coded as 1-any violence exposure reported, or 0- no violence exposure reported. Finally, respondents who indicated they did not want to reply to these questions were coded as a third category - chose not to answer. 
ASK BLACK MOTHERS ABOUT VIOLENCE IN COVID-19

\section{Depression \& Anxiety Symptoms}

Depression and anxiety symptoms were assessed using the PROMIS scales (Pilkonis et

al., 2011). There were 8 items each for depression and anxiety symptoms, respectively, for a total of 16 items. Responses were on a Likert scale from 1- never to 5- always. Sample items for depression and anxiety symptoms, respectively, were I felt I had nothing to look forward to and My worries overwhelmed me. Internal consistency in this sample were excellent for depression symptoms $(\alpha=.950)$ and anxiety symptoms $(\alpha=.953)$. Continuous mean score variables were calculated and used in analyses. Both the depression and anxiety scales are scored such that higher scores reflect higher levels of depressive and anxiety symptomology. The PROMIS is a widely used scale with established psychometric properties. It has been shown to have acceptable reliability $(\alpha>$.9) in ethnically diverse samples (Teressi et al., 2016). Kudel and colleagues (2019) have established the convergent validity of the PROMIS with the respective subscales positively correlating with the Beck Depression Inventory $(r=.73, p<.001)$ and the Beck Anxiety Inventory $(r=.52)$. In a separate study, the PROMIS was found to have strong convergent validity with the depression and anxiety subscales correlating with the Mental Health Components of the SF-12 ( $r=.60$ and $r=.64$ respectively) and strong discriminant validity $(r>$ .20) with the Physical Health Components of the SF-12 (Quach et al., 2016).

\section{Participant Reactions to Violence Research}

At the end of the survey, participants answered three questions about their research participation (DePrince \& Freyd, 2006). With a Likert scale of 1- much more distressing and 5much less distressing, the first item was: For the questions that were asked about different experiences you may have had such as exposure to violence, please rate whether you found answering these questions to be more or less distressing than other things you sometimes 
ASK BLACK MOTHERS ABOUT VIOLENCE IN COVID-19

encounter in day-to-day life. The second item had a Likert scale of 1-definitely not important to 5- definitely important: For the questions that were asked about different experiences you may have had such as exposure to violence, please rate how important you believe it is for researchers to ask about these types of events in order to study the impact of such experiences. The final question assessed support of violence measures in research, from 1- very bad to 5- very good: For the questions that were asked about different experiences you may have had such as exposure to violence, please consider both your experience answering the questions, and your feelings about how important it is we ask the questions, and then rate how good of an idea it is to include such measures in research. Mean scores of each item were created and used in analyses. The items are utilized as single-item measures rather than as indicators of an underlying latent construct or overall scale score. Each item is scored such that higher values indicate greater affirmation of the item in question.

\section{Data Analysis Plan}

Data will be analyzed using a combination of contingency table analyses and t-tests. To test hypotheses related to violence exposure and reactions to participating in violence research, we will use contingency tables and chi-square tests, including Fisher's exact tests where applicable, given the relatively small cell sizes of some questions. Fisher's exact test is a chi-square distributed test that is most appropriate when there are expected cell counts less than $N=5$ (Camilli \& Hopkins, 1978). For all analyses, an a priori alpha level of .05 was used for determination of significant effects. We did not have an established criterion for an a priori effect size given the nature of this study. However, in situating this research from a policy perspective, we would interpret small effect sizes $(d<.2)$ with caution.

\section{Results}


ASK BLACK MOTHERS ABOUT VIOLENCE IN COVID-19

\section{Preliminary Analysis and Data Screening}

The descriptive statistics for all study variables are presented in Table 2.

\section{Insert Table 2 about here}

Missing data on key variables at Wave 1 ranged from $4.5 \%$ to $9 \%$. The rate of attrition from Wave 1 to Wave 2 was 53\%, however, there was no association between Wave 2 attrition and demographic characteristics. Importantly, there was no association between rates of physical violence or forced sexual contact experiences and attrition at Wave 2. The Shapiro-Wilk's test was conducted on the participant reactions to research measures, with none of them meeting the assumption of normality; distress $(S-W=.794, p>.001)$, importance $(S-W=.849, p>.001)$, and support $(S-W=.805, p>.001)$. As a result, these variables will be treated as ordinal data for the purposes of further analyses.

\section{Descriptive Statistics: Violence Exposure \& Shelter-in-Place}

We first examined the relationship between violence exposure and shelter in place orders due to the COVID-19 pandemic. Both the physical and sexual violence items had relatively low rates of occurrence before shelter-in-place orders were issued, after shelter-in-place orders, and during the ensuing 5-months post shelter-in-place orders (see Table 1). Indeed, only one respondent indicated that they had experienced forced sexual contact before the shelter-in-place and did not report these experiences during the latter two time-periods. It is important to note, however, that 7 and 9 respondents respectively indicated that they preferred not to answer the violence items. 
ASK BLACK MOTHERS ABOUT VIOLENCE IN COVID-19

While the low rate of reported occurrence for exposure to violence preclude reliable statistical inferences to be made, there were enough responses to make some descriptive assertions. We did see an increase in the number of participants indicating that they had experienced violence after the shelter-in-place orders were issued (5.1\% to $7.9 \%)$ but returned to before shelter-in-place levels over the summer (4.6\%). However, of those reporting experiences with violence, one-third reported that the abuse got worse after the shelter-in-place orders were issued.

Insert Figure 3 about here

\section{Hypotheses}

We next looked at the participant reactions to being asked about violence during the COVID-19 pandemic. In line with Hypotheses 1a, we found that only $16 \%$ of respondents reported that they felt the questions were distressing. Hypotheses $2 \mathrm{a}$ and $3 \mathrm{a}$ were partially supported, with moderate, as opposed to high, rates of perceived importance $(50 \%)$ and support for violence research (49\%; Figure 3). Thus, despite the current context of COVID-19 and antiBlack violence, approximately half of participants reported importance and support of violence research. Moreover, the majority of participants did not find answering these questions overly distressing.

Our second set of hypotheses was that participants who indicated exposure to violence in the home before, during, or after the shelter-in-place orders would have significantly higher rates of distress, perceived importance, and support for violence research. Figure 4a-c present the distribution of responses to these three items by group: exposure to violence (yes), exposure to 
ASK BLACK MOTHERS ABOUT VIOLENCE IN COVID-19

violence (no), and chose not to answer (NA). Because the number of participants that reported violence experiences was relatively small, we employed a Fisher's exact test to assess the differences in proportional responses between groups. As predicted in Hypothesis $1 \mathrm{~b}$, the group that reported exposure to violence was significantly more likely to report distress $(p=.043)$. In support of Hypothesis $2 \mathrm{~b}$, those exposed to violence had significantly higher rates of perceived importance of violence research $(p=.050)$. Finally, contrary to Hypothesis $3 b$, there were no group differences in support of violence research generally $(p=.373)$.

Insert Figures $4 \mathrm{a}$ about here

Insert Figures $4 \mathrm{~b}$ about here

Insert Figures 4c about here

In order to explore the mental health differences in participants' reactions to research, we conducted independent sample t-tests with bootstrapped standard errors to adjust for the nonnormality of the depression and anxiety symptoms distributions. The group that reported higher levels of distress had significantly higher mean levels of depression $(t(46)=2.599, p=.015)$ and anxiety $(t(46)=3.838, p>.001)$. However, there were no mental health differences between groups on perceived importance or support for violence research (Table 3). 
ASK BLACK MOTHERS ABOUT VIOLENCE IN COVID-19

Insert Table 3 about here

\section{Discussion}

The COVID-19 pandemic combined with the increased awareness of anti-Black violence in the U.S. provide the backdrop for Black/African American mothers' exposure to violence in the home in 2020. With all these societal stress, pressures, and deaths, professionals' desire to not contribute harm is likely strong. Though the research to date overwhelmingly shows that participating in violence research is not harmful (e.g., Gómez et al., 2015), such research cannot address the current differential context for Black/African American mothers. Therefore, the purpose of the current study was to examine Black/African American mothers' levels of distress, perceived importance, and perceived support for this work following participating in research that inquired about their exposure to violence before, during, and since shelter-in-place orders.

Contrary to our expectations, Black/African American mothers' reported rates of violence exposure before, during, and after shelter-in-place were relatively low (14\%). The reasons for these reduced rates are unclear. First, it is possible there are indeed low rates of violence in the home during COVID-19. However, false negatives - that is, denying violence on the surveys even though it is happening in the home-is also possible due to a host of factors, including cultural mistrust of the researchers who are likely presumed to be White (e.g., Lyons et al., 2012).

In line with Hypothesis 1, over $80 \%$ of the total sample reported low levels of distress, with approximately 1 in 3 Black/African American mothers with violence exposure indicating distress. Though existing research has shown that such distress is typically mild and transitory (e.g., Becker-Blease \& Freyd, 20076; Black \& Black, 2007; Cook et al., 2011; DePrince \& Chu, 
ASK BLACK MOTHERS ABOUT VIOLENCE IN COVID-19

2008; Edwards et al., 2009; Galea et al., 2005; Gómez et al., 2015), the rates of reported distress

here do warrant further examination (see Limitations \& Future Directions).

Partially supporting Hypothesis 2, half of the total sample indicated that violence research was important, with all Black/African American mothers with violence histories indicating importance of violence research. These finding bolster the existing literature that shows that participants believe in the importance of violence research (e.g., Cook et al., 2015; Cromer et al., 2006; DePrince \& Freyd, 2006; Edwards et al., 2007; Gómez et al., 2015; Yeater et al., 2012).

Our findings were also in line with Hypothesis 3 regarding support for violence measures in research in the context of weighing the amount of their own distress and perceived importance of the work. Though approximately half of the total sample endorsed support for violence research, over $80 \%$ of Black/African American mothers who reported being exposed to violence indicated such support. Though aligned with past research (e.g., Yeater et al., 2012), this finding is particularly promising, given the context of the double pandemic of COVID-19 and anti-Black violence in the U.S.

Finally, we explored mental health differences in reactions to participation, finding that those who reported higher levels of distress had significantly higher average levels of depression and anxiety symptoms. There were no differences in mental health on perceived importance or support for violence research. These findings, though exploratory, add to the literature in this area by specifically focusing on another factor, mental health, that may contribute to participants' experiences and perceptions of violence research.

\section{Implications for Researchers, Clinicians, \& Community Healthcare Practitioners}


ASK BLACK MOTHERS ABOUT VIOLENCE IN COVID-19

Findings from the current study have implications for how Black/African American mothers are treated across a variety of institutions and contexts. Specifically, questions about violence exposure can and should be asked of Black/African American mothers, even amidst the increased stress of COVID-19 and anti-Black racism. Simply put, assessing for exposure to violence can provide avenues for resource access and utilization, as well guiding traumainformed practices and protocols. Excluding queries about violence exposure may be a form of institutional betrayal (e.g., Smith \& Freyd, 2014) by causing harm through omission during our professional roles. Instead, each of us can engage in institutional courage (Freyd, 2014; Freyd \& Smidt, 2019) by using our roles as researchers, clinicians, and community healthcare practitioners to assess for past and present exposure of violence, which we then use to inform next steps.

Community researchers, even those whose work does not focus on violence, need to ask about violence exposure because of the association with mental, physical, and behavioral health. Researchers outside of trauma psychology can utilize state of the art measures (e.g., Goldberg \& Freyd, 2006; author citation) to ask behaviorally about violence exposure in order to limit false negatives that come from the use of accurate, but stigmatizing, language, such as rape. Furthermore, researchers can assess participants' reactions to engaging in such research with the three items utilized in the current study (DePrince \& Freyd, 2006). To elicit additional information, researchers could include one or two open-ended qualitative items that can provide richer information on experiences of distress, perceived importance, and support for violence research (DePrince \& Freyd, 2006). Doing so not only continually provides information on participants' experiences across developmental, cultural, and methodological contexts, but also 
ASK BLACK MOTHERS ABOUT VIOLENCE IN COVID-19

provides evidence for research team members, IRBs, and others who are worried about the harm that asking about violence exposure could cause participants.

Similar to how non-violence researchers should still include violence measures in their work, clinicians — regardless of clients' presenting problems — should ask about past and present exposure to violence. Many prospective clients seek therapy due to a variety of concerns, such as depression, anxiety, self-injury, eating disorders, and relationship problems — without mentioning the violence they have experienced. This disguised presentation of violence exposure (Herman, 1997) can influence clinicians in directions of therapeutic care that are not trauma-informed. Moreover, regardless of a client's experiences of violence, speaking of violence can serve to further de-stigmatize victimization. Finally, for clients with past or present exposure to violence, trauma-informed and culturally congruent care should incorporate the context of inequality, violence exposure, and cultural norms into case conceptualization and treatment planning. Utilizing contextualized frameworks, such as cultural betrayal trauma theory (e.g., Gómez \& Gobin, 2020) to aid in case conceptualization within trauma-informed care, such as relational cultural therapy (e.g., Gómez et al., 2016; Gómez, 2020b; Jordan, 2010; Miller, 1976; Miller \& Stiver, 1997), may be particularly beneficial for Black/African American mothers who have experienced violence in the context of intersectional (Crenshaw, 1989, 1991) racist and sexist oppression.

Finally, community healthcare practitioners can ask screener items for violence exposure, such as Do you feel safe at home?, with follow up items for affirmative responses. As indicated, practitioners can provide patients with community-based resources, such as national hotlines and culturally competent mental health settings, such as the SASHA Center (Sexual Assault Services 
ASK BLACK MOTHERS ABOUT VIOLENCE IN COVID-19

for Holistic Healing \& Awareness), an African American non-profit organization serving the African American community in Detroit, Michigan (SASHA Center, 2020).

\section{Limitations \& Future Directions}

The current study provides important information about how Black/African American mothers emotionally react and appraise violence research following participation during the COVID-19 pandemic. Nevertheless, future research can build upon the current study's limitations. The current study operationalized violence history with four items assessing relatively recent physical or sexual violence_-before, during, and after shelter-in-place governmental guidelines. Therefore, it is unknown how exposure to violence in childhood, adolescence, and years past impact reactions to research participation. Therefore, future research can examine a wider range of kinds of violence with culturally congruent methodology, such as the Cultural Betrayal Multidimensional Inventory for Black American Young Adults (author citation). While we have presented statistical tests that are less biased in situations with small cell sizes (e.g., Fisher's exact), these results should still be taken as descriptive in nature and should be confirmed on larger samples with higher proportions of violence exposure.

Importantly, violence exposure was assessed with self-report responses as part of a larger data collection effort that did not involve a process of building community rapport and earning institutional trust. Therefore, our lower rates of violence exposure in this sample may be a function of cultural mistrust. While not overstating risk to participants in informed consent materials (Abu-Rus et al., 2019), future research can employ a research process that includes steps to earn trust (Rahill et al., 2018), as well as using a mixed-method design with Black women interviewers in order determine if cultural trust facilitates increased disclosure of violence, as has been found in prior studies (e.g., Lyons et al., 2011). Finally, researchers can 
ASK BLACK MOTHERS ABOUT VIOLENCE IN COVID-19

qualitatively probe for more information regarding the nature of distress felt by those who experienced violence, as well as longitudinally tracking feelings of distress, as well as post-study behaviors, such as help-seeking.

\section{Concluding Thoughts}

The double pandemic of COVID-19 and police- and civilian-perpetrated anti-Black violence in 2020 continues to harm Black/African American communities (e.g., CDC, 2020). Within this context, Black/African American mothers are also at risk for experiencing violence in the home. An impulse of researchers and community practitioners may be to refrain from inquiring about violence in line with the noble goal of doing no harm (e.g., Becker-Blease \& Freyd, 2006, 2007), perhaps particularly to Black/African American mothers who are enduring increased hardships due to societal inequality. However, the costs of not asking are profound and include committing institutional betrayal (Smith \& Freyd, 2014) by promoting silence, while not having adequate information to engage in trauma-informed research and treatment. Fortunately, the current study provides evidence that even in the context of 2020, inquiring about violence is not more distressing than other day to day experiences for the majority of Black/African American mothers, including those who have been recently victimized. Moreover, our study shows that Black/African American mothers, especially those with violence histories, assert that violence research is important and should be included in studies. Therefore, even during a time of extreme psychological trauma, sickness, and death, researchers and community practitioners can engage in institutional courage (Freyd \& Smidt, 2019) through incorporating the reality of violence into our work with Black/African American mothers. In doing so, we are better equipped to provide trauma-informed and culturally congruent work that can result in radical healing (French et al., 2020) that can benefit all of the Black community. 
ASK BLACK MOTHERS ABOUT VIOLENCE IN COVID-19

\section{References}

Abu-Rus, A., Bussell, N., Olsen, D. C., Davis-Ku, M. A. A. L., \& Arzoumanian, M. A. (2019). Informed consent content in research with survivors of psychological trauma. Ethics \& Behavior, 29(8), 595-606.

Ahrens, C. E. (2006). Being silenced: The impact of negative social reactions on the disclosure of rape. American Journal of Community Psychology, 38(3-4), 263-274. https://10.1007/s10464-006-9069-9

Alexander, M. (2012). The new Jim crow: Mass incarceration in the age of colorblindness. New York: The New Press.

American Psychological Association (2020). How COVID-19 may increase domestic violence and child abuse. https://www.apa.org/topics/covid-19/domestic-violence-child-abuse

Bailey, M. (2016). Misogynoir in medical media: On Caster Semenya and R. Kelly. Catalyst: Feminism, Theory, Technoscience, 2(2), 1-31. https://doi.org/10.28968/cftt.v2i2.28800

Becker-Blease, K., \& Freyd, J. (2006). Research participants telling the truth about their lives:

The ethics of asking and not asking about abuse. American Psychologist, 61(3), 218-226.

Becker-Blease, K., \& Freyd, J. J. (2007). The ethics of asking about abuse and the harm of “don't ask, don't tell.” American Psychologist, 62(4), 330-332. http://10.1037/0003-

\section{$\underline{066 X .62 .4 .330}$}

Bell, C. C., \& Mattis, J. (2000). The importance of cultural competence in ministering to African American victims of domestic violence. Violence Against Women, 6(5), 515-532. https://doi.org/10.1177/10778010022182001

Bent-Goodley, T. B. (2001). Eradicating domestic violence in the African American community: A literature review and action agenda. Trauma, Violence, \& Abuse, 2(4), 316-330. 
ASK BLACK MOTHERS ABOUT VIOLENCE IN COVID-19

Black, M., \& Black, R. (2007). A public health perspective on "The ethics of asking and not asking about abuse." American Psychologist, 62(4), 328-239.

Camilli, G., \& Hopkins, K. D. (1978). Applicability of chi-square to $2 \times 2$ contingency tables with small expected cell frequencies. Psychological Bulletin, 85(1), 163-167. https://doi.org/10.1037/0033-2909.85.1.163

Campbell, J. (2020). Coronavirus and domestic violence: What you should know. Johns Hopkins Medicine. https://www.hopkinsmedicine.org/health/conditions-anddiseases/coronavirus/coronavirus-and-domestic-violence-what-you-should-know

Campbell, R. (2009). Science, social change, and ending violence against women: which one of these is not like the others? Violence Against Women, 15(4), 434-439.

Centers for Disease Control (April, 2020). COVIDView: A weekly surveillance summary of U.S. COVID-19 activity. https://www.cdc.gov/coronavirus/2019-ncov/coviddata/covidview/index.html\#mortality

Cook, S. L., Darnell, D., Anthony, E. R., Tusher, C. P., Zimmerman, L., Enkhtor, D., \& Hipp, T. N. (2011). Investigating the effects of trauma-related research on well-being. Accountability in Research, 18(5), 297-322.

Cook, S. L., Swartout, K. M., Goodnight, B. L., Hipp, T. N., \& Bellis, A. L. (2015). Impact of violence research on participants over time: Helpful, harmful, or neither? Psychology of Violence, 5(3), 314-324. https://10.1037/a0038442

Crenshaw, K. (1989). Demarginalizing the intersection of race and sex: A Black feminist critique of antidiscrimination doctrine, feminist theory and antiracist politics. The University of Chicago Legal Forum, 140, 139-167. 
ASK BLACK MOTHERS ABOUT VIOLENCE IN COVID-19

Crenshaw, K. (1991). Mapping the margins: intersectionality, identity politics, and violence against women of color. Stanford Law Review, 43, 1241-1299.

Cromer, L., Freyd, J. J., Binder, A. K., DePrince, A. P., \& Becker- Blease, K. (2006). What's the risk in asking? Participant reaction to trauma history questions compared with reaction to other personal questions. Ethics \& Behavior, 16(4), 347-363.

Dalenberg, C. (2013). Trauma research and the institutional review board, executive committee, Division 56, June 15, 2013. Trauma Psychology Newsletter: An Official Publication of Division 56 of the American Psychological Association, fall issue, 43-49.

DePrince, A.P, Brown, L.S., Cheit, R.E., Freyd, J.J., Gold, S.N., Pezdek, K. \& Quina, K (2012). Motivated forgetting and misremembering: Perspectives from Betrayal Trauma Theory. In Belli, R. F. (Ed.), True and False Recovered Memories: Toward a Reconciliation of the Debate (Nebraska Symposium on Motivation 58) (pp 193-243). New York: Springer.

DePrince, A. P., \& Chu, A. (2008). Perceived benefits in trauma research: Examining methodological and individual difference factors in responses to research participation. Journal of Empirical Research on Human Research Ethics, 3(1), 35-47.

DePrince, A. P. \& Freyd, J. J. (2006). Costs and benefits of being asked about trauma history. Journal of Trauma Practice, 3(4), 23-35.

Dreyer, B. P., Trent, M., Anderson, A. T., Askew, G. L., Boyd, R., Coker, T. R., ... \& MontoyaWilliams, D. (2020). The death of George Floyd: Bending the arc of history towards justice for generations of children. Pediatrics, Article e2020009639. https://doi.org/10.1542/peds.2020-009639 
ASK BLACK MOTHERS ABOUT VIOLENCE IN COVID-19

Edwards, V., Dube, S., Felitti, V., \& Anda, R. (2007). It's ok to ask about past abuse. American Psychologist, 62(4), 327-328.

Evans, M. L., Lindauer, M., \& Farrell, M. E. (2020). A Pandemic within a Pandemic-Intimate Partner Violence during Covid-19. Advanced online publication. New England Journal of Medicine.

Fontes, L. A. (2004). Ethics in violence against women research: The sensitive, the dangerous, and the overlooked. Ethics \& Behavior, 14(2), 141-174. https://10.1207/s15327019eb1402_4

French, B. H., Lewis, J. A., Mosley, D. V., Adames, H. Y., Chavez-Dueñas, N. Y., Chen, G. A., \& Neville, H. A. (2020). Toward a psychological framework of radical healing in communities of color. The Counseling Psychologist, 48(1), 14-46. https://doi.org/10.1177\%2F0011000019843506

Freyd, J. J. (2014, July 14). Official campus statistics for sexual violence mislead. Aljazeera America. http://america.aljazeera.com/opinions/2014/7/college-campus$\underline{\text { sexualassaultsafetydatawhitehousegender.html }}$

Freyd, J. J., \& Smidt, A. M. (2019). So you want to address sexual harassment and assault in your organization? Training is not enough; Education is necessary. Journal of Trauma \& Dissociation, 20, 489-494.

Galea, S., Nandi, A., Stuber, J., Gold, J., Acierno, R., Best, C., Bucuvalas, M., Rudenstine, S., Boscarino, J., \& Resnick, H. (2005). Participant reactions to survey research in the general population after terrorist attacks. Journal of Traumatic Stress, 18(15), 461-465.

Gleaves, D. H., Rucklidge, J. J., \& Follette, V. M. (2007). What are we teaching our students by not asking about abuse? American Psychologist, 62(4), 326- 327. 
ASK BLACK MOTHERS ABOUT VIOLENCE IN COVID-19

Goldberg, L. R. \& Freyd, J. J. (2006). Self-reports of potentially traumatic experiences in an adult community sample: Gender differences and test-retest stabilities of the items in a Brief Betrayal-Trauma Survey. Journal of Trauma \& Dissociation, 7(3), 39-63.

Gómez, J. M. (2015). Microaggressions and the enduring mental health disparity: Black Americans at risk for institutional betrayal. Journal of Black Psychology, 41(2), 121-143. https://doi.org/10.1177/0095798413514608

Gómez, J. M. (2017a). Does ethno-cultural betrayal in trauma affect Asian American/Pacific Islander college students' mental health outcomes? An exploratory study. Journal of American College Health, 65(6), 432-436.

https://doi.org/10.1080/07448481.2017.1341896

Gómez, J. M. (2017b). Does gender matter? An exploratory study of cultural betrayal trauma and hallucinations in Latino undergraduates at a predominantly White university. Advanced online publication. Journal of Interpersonal Violence. https://doi.org/10.1177/0886260517746942

Gómez, J. M. (2019a). Group dynamics as a predictor of dissociation for Black victims of violence: An exploratory study of cultural betrayal trauma theory. Transcultural Psychiatry, 56(5), 878-894. https://doi.org/10.1177/1363461519847300

Gómez, J. M. (2019b). Isn't it all about victimization? (Intra)cultural pressure and cultural betrayal trauma in ethnic minority college women. Violence Against Women, 25(10), 1211-1225. https://doi.org/10.1177/1077801218811682

Gómez, J. M. (2019c). What's in a betrayal? Trauma, dissociation, and hallucinations among high-functioning ethnic minority emerging adults. Journal of Aggression, Maltreatment \& Trauma, 28(10), 1181-1198. https://doi.org/10.1080/10926771.2018.1494653 
ASK BLACK MOTHERS ABOUT VIOLENCE IN COVID-19

Gómez, J. M. (2019d). What's the harm? Internalized prejudice and intra-racial trauma as cultural betrayal among ethnic minority college students. American Journal of Orthopsychiatry, 89, 237-247. https://doi.org/10.1037/ort0000367

Gómez, J. M. (2020a). Cultural betrayal as a dimension of traumatic harm: Violence \& PTSS among ethnic minority emerging adults. Advanced Online Publication. Journal of Child \& Adolescent Trauma. https://doi.org/10.1007/s40653-020-00314-0

Gómez, J. M. (2020b). Trainee perspectives on relational cultural therapy and cultural competency in supervision of trauma cases. Journal of Psychotherapy Integration, 30(1), 60-66. https://doi.org/10.1037/int0000154

Gómez, J. M., Becker-Blease, K., \& Freyd, J. J. (2015). A brief report on predicting self-harm: Is it gender or abuse that matters? Journal of Aggression, Maltreatment, \& Trauma, 24(2), 203-214. https://10.1080/10926771.2015.1002651

Gómez, J. M., \& Freyd, J. J. (2018). Psychological outcomes of within-group sexual violence: Evidence of cultural betrayal. Journal of Immigrant \& Minority Health, 20(6), 14581467. https://doi.org/10.1007/s10903-017-0687-0

Gómez, J. M., \& Gobin, R. L. (2020). Black women and girls \& \#MeToo: Rape, cultural betrayal, \& healing. Sex Roles: A Journal of Research, 82(1), 1-12. https://doi.org/10.1007/s11199-019-01040-0

Gómez, J. M., Lewis, J. K, Noll, L. K., Smidt, A. M., \& Birrell, P. J. (2016). Shifting the focus: Nonpathologizing approaches to healing from betrayal trauma through an emphasis on relational care. Journal of Trauma \& Dissociation [Special Section], 17(2), 165-185. https://doi.org/10.1080/15299732.2016.1103104 
ASK BLACK MOTHERS ABOUT VIOLENCE IN COVID-19

Gómez, J. M., Smith, C. P., \& Freyd, J. J. (2014). Zwischenmenschlicher und institutioneller verrat [Interpersonal and institutional betrayal]. In R. Vogt (Ed.), Verleumdung und Verrat: Dissoziative Störungen bei schwer traumatisierten Menschen als Folge von Vertrauensbrüchen (pp. 82-90). Roland, Germany: Asanger Verlag.

Griffin, M. G., Resick, P. A., Waldrop, A. E., \& Mechanic, M. B. (2003). Participation in trauma research: Is there evidence of harm? Journal of Traumatic Stress, 16(3), 221-227.

Herman, J. L. (1997). Trauma and recovery. New York, NY: Basic Books.

Holland, K. J., Cortina, L. M., Magley, V. J., Baker, A. L., \& Benya, F. F. (2020). Don’t let COVID-19 disrupt campus climate surveys of sexual harassment. PNAS, 117. https://doi/10.1073/pnas.2018098117

Hooper, M. W., Nápoles, A. M., \& Pérez-Stable, E. J. (2020). COVID-19 and racial/ethnic disparities. Jama, 323(24), 2466-2467. https://doi.org/10.1001/jama.2020.8598

Institute of Medicine. (2002). Unequal treatment: Confronting racial and ethnic dis- parities in health care. Washington, DC: National Academy of Science.

Jordan, J. V. (2010). Relational-cultural therapy. Washington, DC: American Psychological Association.

Kudel, I, Pona, A., Cox, S., Szoka, N., Tabone, L., \& Brode, C. "Psychometric properties of NIH PROMIS ${ }^{\circledR}$ instruments in bariatric surgery candidates." Health Psychology 38, no. 5 (2019): 359 .

Laurencin, C. T., \& McClinton, A. (2020). The COVID-19 pandemic: A call to action to identify and address racial and ethnic disparities. Journal of Racial and Ethnic Health Disparities, 1-5. Advanced Online Publication. https://dx.doi.org/10.1007\%2Fs40615-020-00756-0

Lyons, H. Z., Bike, D. H., Johnson, A., \& Bethea, A. (2012). Culturally competent qualitative 
ASK BLACK MOTHERS ABOUT VIOLENCE IN COVID-19

research with people of African descent. Journal of Black Psychology, 38(2), 153-171.

Miller, J. B. (1976). Toward a new psychology of women. Boston, MA: Beacon Press.

Miller, J. B., \& Stiver, I.P. (1997). The healing connection: How women form relationships in therapy and in life. Boston, MA: Beacon Press.

Neville, H. A., \& Pugh, A. O. (1997). General and culture-specific factors influencing African American women's reporting patterns and perceived social support following sexual assault: An exploratory investigation. Violence Against Women, 3(4), 361-381. https://doi.org/10.1177/1077801297003004003

Pilkonis, P. A., Choi, S. W., Reise, S. P., Stover, A. M., Riley, W. T., Cella, D., \& PROMIS Cooperative Group. (2011). Item banks for measuring emotional distress from the Patient-Reported Outcomes Measurement Information System (PROMIS®): depression, anxiety, and anger. Assessment, 18(3), 263-283.

Rahill, G. J., Joshi, M., \& Shadowens, W. (2018). Best intentions are not best practices: lessons learned while conducting health research with trauma-impacted female victims of nonpartner sexual violence in Haiti. Journal of Black psychology, 44(7), 595-625.

Ruiz, E., Ruvalcaba, Y., Berenstain, N., \& Fluegeman, S. (2020). Measuring the economic impact of COVID-19 on survivors of Color. https://metoomvmt.org/wpcontent/uploads/2020/11/MeTooFreeFrom_CovidImpactReport2020.pdf

SASHA Center (2020). SASHA Center: Healing is possible. https://www.sashacenter.org/\#

Smith, C.P., \& Freyd, J.J. (2014). Institutional betrayal. American Psychologist, 69(6), 575-587.

Snowden, L. R., \& Yamada, A. (2005). Cultural differences in access to care. Annual Review of Clinical Psychology, 1, 143-166. 
ASK BLACK MOTHERS ABOUT VIOLENCE IN COVID-19

Teresi, J. A., Ocepek-Welikson, K., Kleinman, M., Ramirez, M., \& Kim, G. (2016). Psychometric properties and performance of the Patient Reported Outcomes Measurement Information System ${ }^{\circledR}$ (PROMIS $\left.{ }^{\circledR}\right)$ Depression short forms in ethnically diverse groups. Psychological Test and Assessment Modeling, 58(1), 141-181.

Tillman, S., Bryant-Davis, T., Smith, K., \& Marks, A. (2010). Shattering silence:

Exploring barriers to disclosure for African American sexual assault survivors. Trauma, Violence, \& Abuse, 11(2), 59-70.

Washington, P. A. (2001). Disclosure patterns of Black female sexual assault survivors. Violence Against Women, 7(11), 1254-1283. https://doi.org/10.1177/10778010122183856

Yeater, E., Miller, G., Rinehart, J., \& Nason, E. (2012). Trauma and sex surveys meet minimal risk standards: Implications for institutional review boards. Psychological Science, 23(7), $780-787$. 
ASK BLACK MOTHERS ABOUT VIOLENCE IN COVID-19

\section{Table 1}

Sociodemographic Characteristics of Participants at Baseline

$\overline{\text { Baseline characteristic Study Sample }}$

$n \quad \%$

Marital status

$\begin{array}{lcc}\text { Single } & 41 & 27.3 \\ \text { Married/partnered } & 34 & 26.8 \\ \text { Divorced/widowed } & 8 & 6.2 \\ \text { Highest educational } & & \\ \quad \text { level } & & \\ \text { <High school } & 12 & 9.5 \\ \text { High school/GED } & 46 & 36.2 \\ \text { Some college } & 34 & 26.8 \\ \text { Associates } & 15 & 11.8 \\ \text { University or } & 18 & 14.2 \\ \quad \text { postgraduate } & & \\ \text { degree } & & \\ \text { Employment } & & \\ \text { Unemployed } & 56 & 44.1 \\ \text { Employed part-time } & 24 & 18.9 \\ \text { Employed full-time } & 39 & 30.7 \\ \text { Self-employed } & 21 & 14.0\end{array}$


ASK BLACK MOTHERS ABOUT VIOLENCE IN COVID-19

\section{Table 2}

Descriptive Statistics for Study Variables

Variable mean(\%Yes) sd skew kurtosis se corr

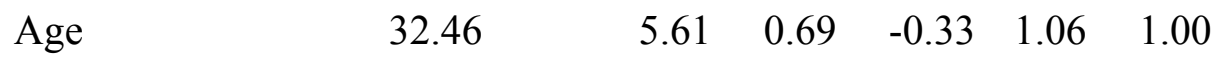

$\begin{array}{lllllll}\text { Distress } & 3.12 & 1.14 & 0.02 & -0.15 & 0.16 & -.198\end{array}$

$\begin{array}{llllllll}\text { Importance } & 3.68 & 1.14 & -0.44 & -0.46 & 0.16 & .044 & .345\end{array}$

$\begin{array}{llllllll}\text { Support } & 3.75 & 1.00 & -0.08 & -0.79 & 0.14 & .204 & .170 .752\end{array}$

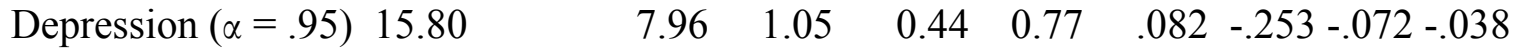

Anxiety $(\alpha=.953) \quad 17.31 \quad \quad 8.44 \quad 0.70 \quad-0.24 \quad 0.81 \quad .047-.329-.085-.003 .846$

BSH P. Viol $\quad(5 \%) \quad$---- $\quad$---- $\quad---$

DSH P. Viol $\quad(5 \%) \quad$---- $\quad$---- ---- $\quad$----

BSH S. Viol $\quad(0.9 \%) \quad$---- $\quad$--- $\quad----\quad$----

DSH S. Viol $\quad(0 \%) \quad$--- $\quad$---- $\quad---$

ASH P. Viol $\quad(8 \%) \quad$--- $\quad$--- $\quad----\quad$---

ASH S. Viol $\quad(0 \%) \quad$--- $\quad$---- ---

Any Violence $\quad(14 \%) \quad$---- $\quad$--- $\quad----\quad$----

BSH: Before Shelter-in-Place

DSH: During Shelter-in-Place ASH: After Shelter-in-Place

P. Viol: Physical Violence

S. Viol: Sexual Violence 
ASK BLACK MOTHERS ABOUT VIOLENCE IN COVID-19

Table 3

Welch's t-test: PROMIS Anxiety and Depression means by Reactions to Trauma Questions

\begin{tabular}{lccccccc}
\hline \multirow{2}{*}{ Reaction } & \multicolumn{2}{c}{ High } & \multicolumn{2}{c}{ Low } & \multirow{2}{*}{$(42.65)$} & $p$ & Cohen's $d$ \\
\cline { 2 - 5 } & $M$ & $S D$ & $M$ & $S D$ & & & \\
\hline Distress & & & & & & & \\
$\quad$ Anxiety & 19.00 & 8.93 & 10.50 & 4.82 & 4.32 & .000 & -1.08 \\
$\quad \begin{array}{l}\text { Depression } \\
\text { Importance }\end{array}$ & 17.08 & 9.16 & 10.75 & 6.58 & 2.60 & .015 & -0.75 \\
$\quad$ Anxiety & 17.65 & 8.36 & 15.74 & 9.27 & 0.77 & .447 & -0.22 \\
$\quad$ Depression & 16.08 & 8.70 & 14.96 & 9.34 & 0.43 & .667 & -0.13 \\
Support & & & & & & & \\
$\quad$ Anxiety & 16.62 & 8.92 & 16.61 & 8.91 & 0.003 & .997 & 0.00 \\
$\quad$ Depression & 15.72 & 8.54 & 15.31 & 9.46 & 0.16 & .872 & -0.05 \\
\hline
\end{tabular}

Figure 1. Adapted Bronfenbrenner Model: Anti-Black Racism \& Cultural Betrayal Trauma, reprinted with permission

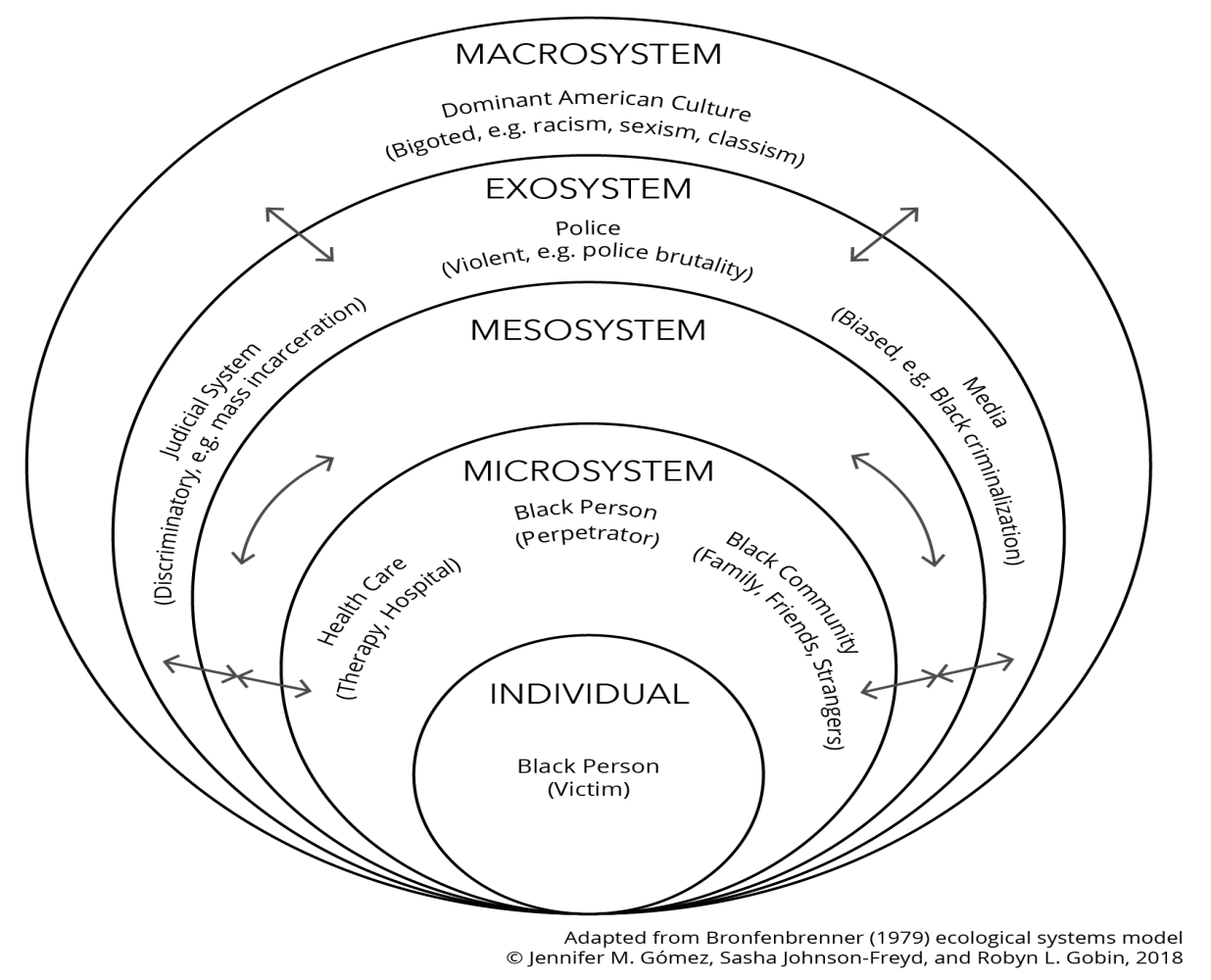


Figure 2. Cultural Betrayal Trauma Theory, reprinted with permission

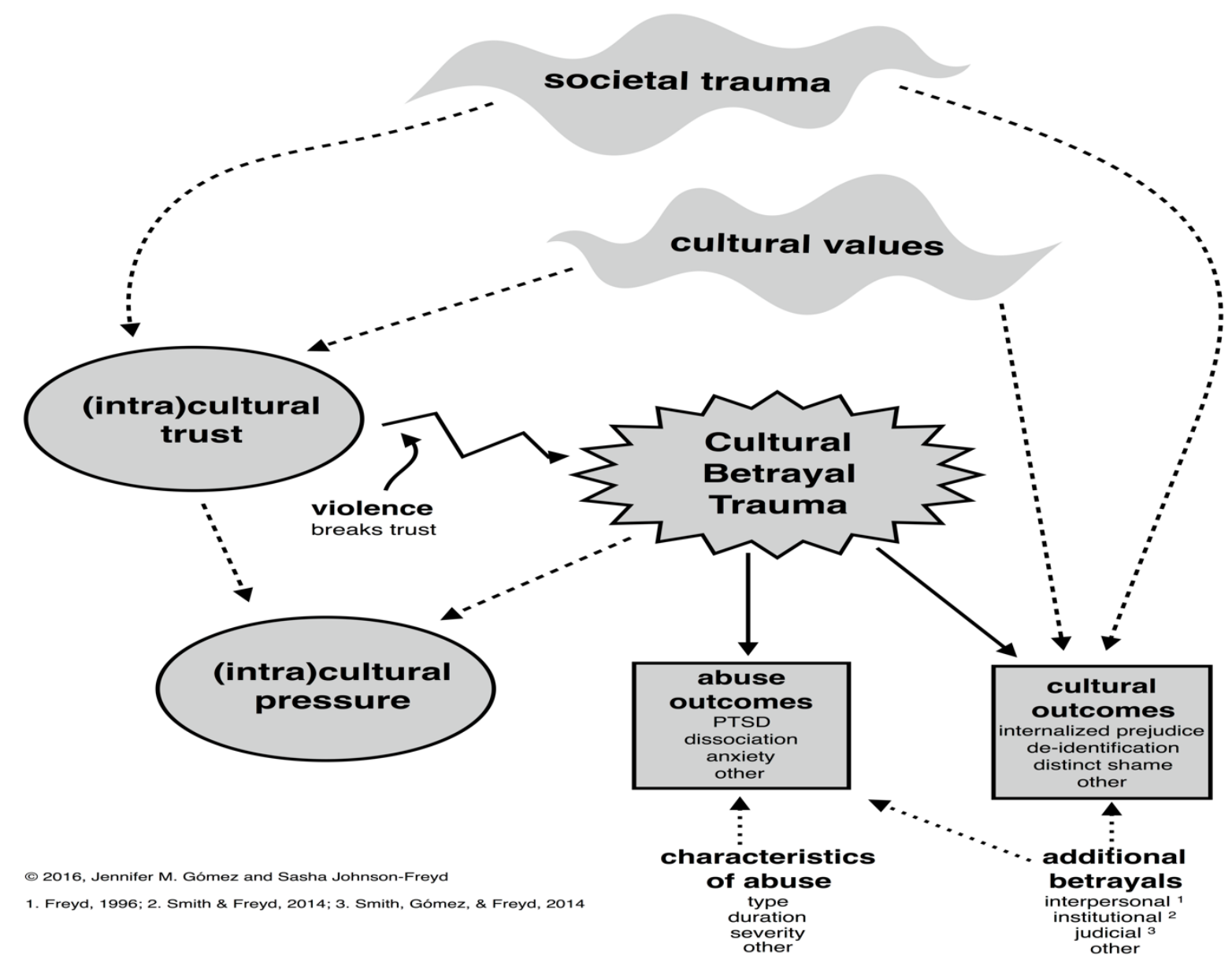


ASK BLACK MOTHERS ABOUT VIOLENCE IN COVID-19

Figure 3. Black mothers' reactions to participating in violence research

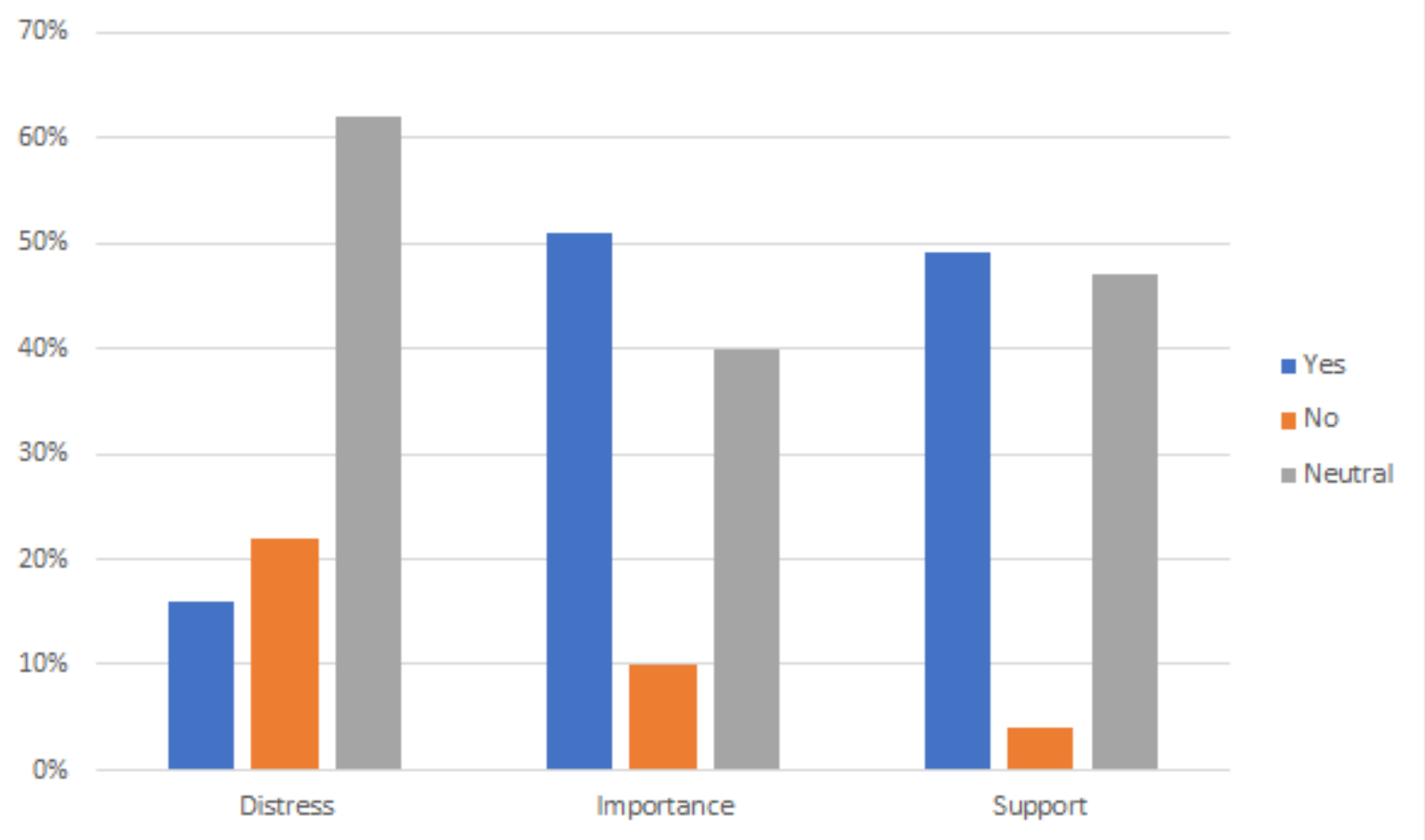

Figure 4a. Black mothers' distress by exposure to violence history

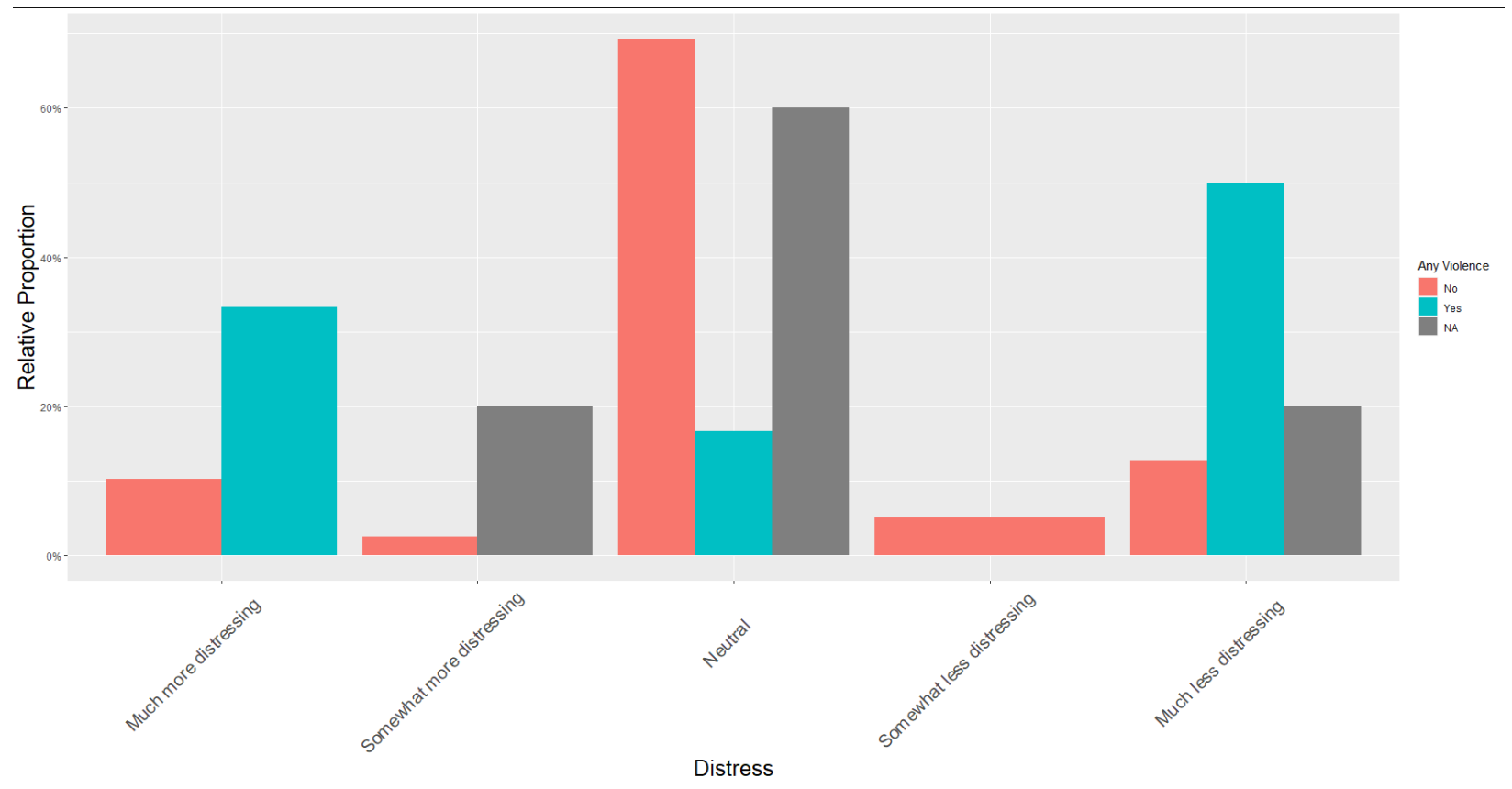


ASK BLACK MOTHERS ABOUT VIOLENCE IN COVID-19

Figure 4b. Black mothers' perceived importance of violence research by exposure to violence

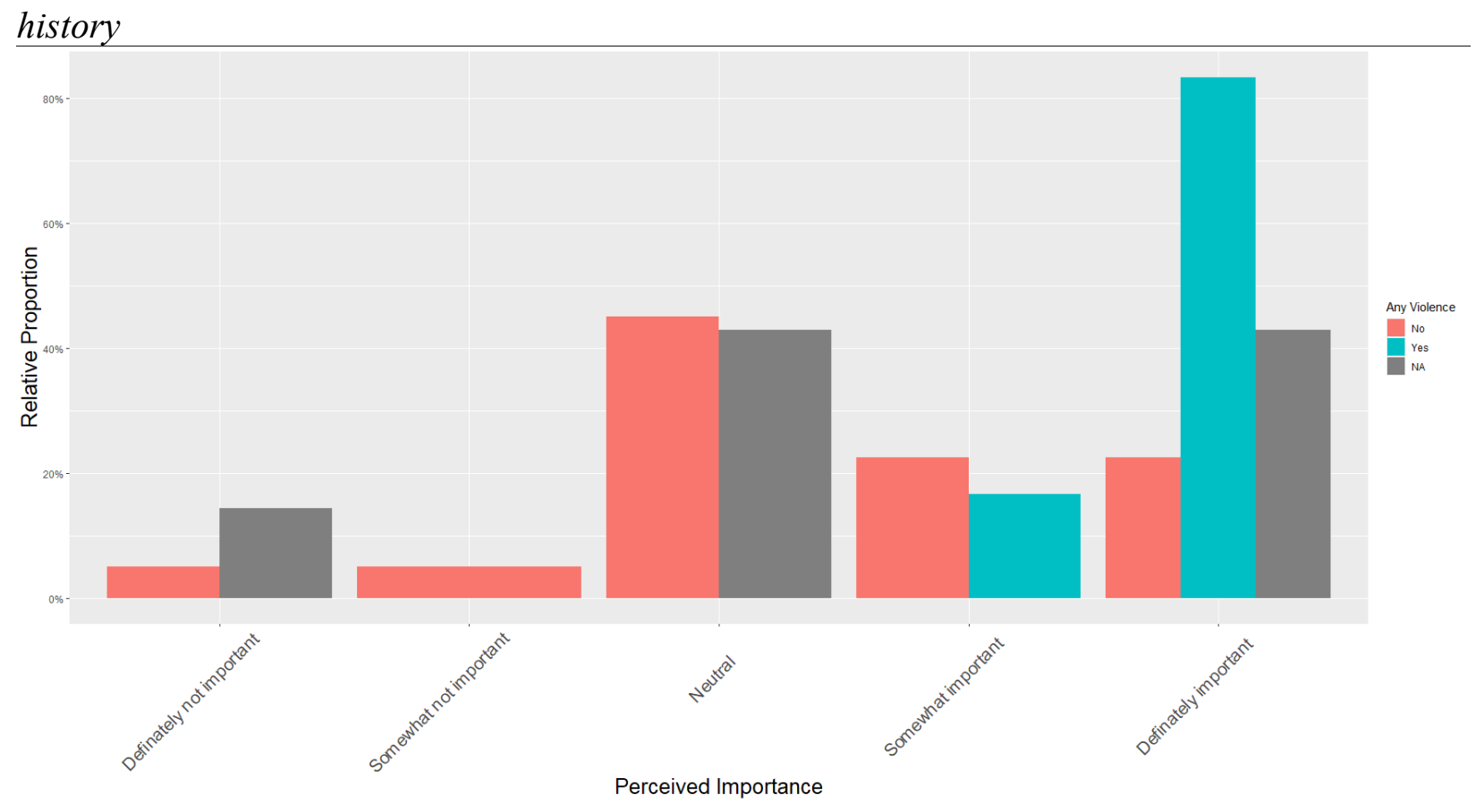

Figure 4c. Black mothers' support of violence research by exposure to violence history

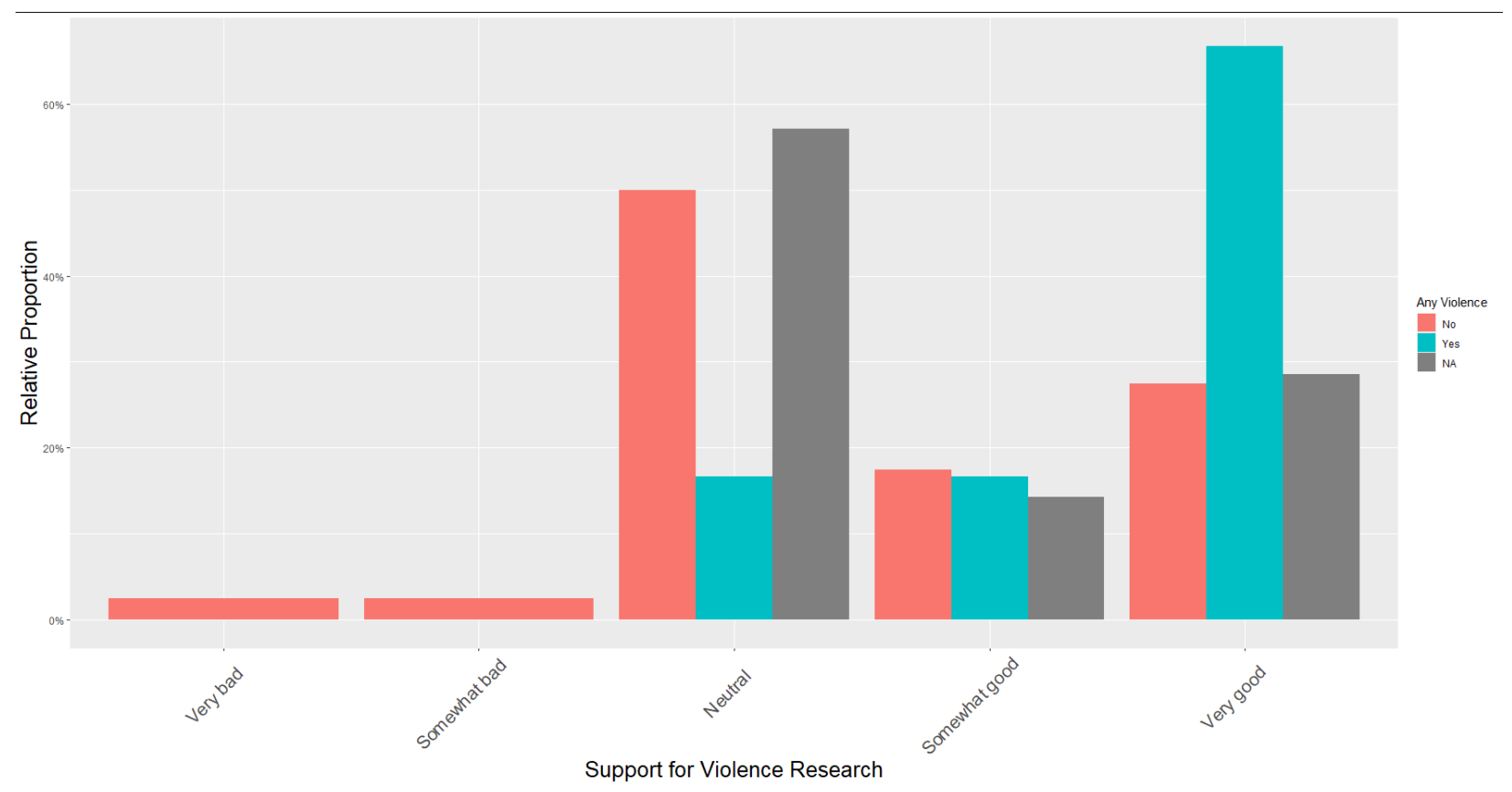

